\title{
Social capital and chronic post-traumatic stress disorder among survivors of the 2007 earthquake in Pisco, Peru
}

\author{
Elaine C. Flores ${ }^{a, b},{ }^{*}, 1$, Andres M. Carnero ${ }^{a, 1}$, and Angela M. Bayer ${ }^{c, d}$ \\ Elaine C. Flores: elaineflores22@hotmail.com; Andres M. Carnero: andrescarnero@gmail.com; Angela M. Bayer: \\ angelabayerx@gmail.com \\ aPostgraduate School, Universidad Peruana Cayetano Heredia, Av. Honorio Delgado 430, San \\ Martin de Porres, Lima 31, Peru \\ bSchool of Medicine, Universidad de San Martin de Porres, Av. Alameda del Corregidor 1531, La \\ Molina, Lima 12, Peru \\ 'School of Public Health and Administration, Universidad Peruana Cayetano Heredia, Av. \\ Honorio Delgado 430, San Martin de Porres, Lima 31, Peru \\ dDivision of Infectious Diseases, David Geffen School of Medicine, University of California, Los \\ Angeles, CA, USA
}

\section{Abstract}

This study aimed to evaluate the association between chronic Post-Traumatic Stress Disorder (PTSD) and both structural and cognitive social capital in adult survivors of the 2007 earthquake in Pisco, Peru. Cognitive social capital measures trust, sense of belonging and interpersonal relationships in the community and structural social capital measures group membership, support from community groups and individuals, and involvement in citizenship activities. We conducted a population-based cross-sectional study in five counties in Pisco, selecting 1012 adults through complex, multi-stage random sampling. All participants completed socio-demographic questions and validated Spanish-language versions of the Adapted Social Capital Assessment Tool (SASCAT) and the civilian PTSD checklist (PCL-C). After performing descriptive and bivariate analyses, we carried out prevalence ratio (PR) regression. The overall prevalence of chronic PTSD was $15.9 \%$ (95\% CI: 12.3, 19.8), much higher than anticipated based on existing evidence. Cognitive social capital was found to be negatively associated with chronic PTSD, while no significant association was found for structural social capital. Specifically, those with high cognitive social capital had an almost two times lower prevalence of chronic PTSD (PR $=1.83$, $95 \%$ CI: 1.50, 2.22) compared with those with low cognitive social capital. No independent association between structural social capital and chronic PTSD was found (PR $=1.44,95 \% \mathrm{CI}$ : $0.70,2.97)$. In conclusion, cognitive social capital, but not structural social capital, has a protective influence on the occurrence of chronic PTSD in survivors of natural disasters. These results may have public health implications. For example, pre- and post-disaster community-based interventions that catalyze and foster dimensions of cognitive social capital may aid in

\footnotetext{
(C) 2013 Elsevier Ltd. All rights reserved.

*Corresponding author. Postgraduate School, Universidad Peruana Cayetano Heredia, Honorio Delgado 430, San Martín de Porres, Lima 31, Peru.

${ }^{1} \mathrm{ECF}$ and AMC contributed equally to this study.
} 
ameliorating the effect of earthquakes and other natural disasters on populations with high vulnerability to such events and poor access to mental health and other support services.

\section{Keywords}

Stress disorders; Post-traumatic; Social capital; Social support; Earthquakes; Peru

\section{Introduction}

Post-traumatic stress disorder (PTSD) is a frequent and debilitating condition arising after exposure to traumatic events, including natural disasters (Davidson \& McFarlane, 2006; Foa, Stein, \& McFarlane, 2006; Galea, Nandi, \& Vlahov, 2005; Neria, Nandi, \& Galea, 2008; Norris et al., 2002). PTSD is characterized by re-experience of trauma, avoidance, numbing and hyper arousal for at least one month, with significant distress and/or functional impairment (Davidson \& McFarlane, 2006; Foa et al., 2006; Yehuda, 2002). Although most PTSD cases resolve themselves in the first year, a considerable proportion of people experience a chronic course spanning many years or even decades, and most chronic cases do not recover completely (Davidson \& McFarlane, 2006; Foa et al., 2006; Kessler, Sonnega, Bromet, Hughes, \& Nelson, 1995). Furthermore, chronic PTSD is associated with long-term physical and psychiatric co-morbidity, psychosomatic symptoms, poor functioning, suicidal behavior and impaired quality of life (McFarlane, 2010; Sareen et al., 2007; Spitzer et al., 2009). Chronic PTSD cases pose a significant burden for society, particularly in developing countries, where most victims of natural disasters are concentrated (International Federation of Red Cross and Red Crescent Societies, 2012) and where the psychiatric prognosis of survivors is generally dimmer than in more developed settings (Davidson \& McFarlane, 2006; Norris et al., 2002).

The enormous burden and disparities between communities in the occurrence of PTSD, like most mental health outcomes, has revived interest in determining the effect of the social context on health. Social capital represents an appealing target for preventive interventions given its potentially beneficial effects on health (Kawachi, Kennedy, Lochner, \& ProthrowStith, 1997; Kripper \& Sapag, 2009; Murayama, Fujiwara, \& Kawachi, 2012; Szreter \& Woolcock, 2004), particularly mental health (Almedom, 2005; De Silva, Huttly, Harpham, \& Kenward, 2007; Kawachi \& Berkman, 2001; Kripper \& Sapag, 2009; McKenzie, Whitley, \& Weich, 2002; Whitley \& McKenzie, 2005). Social capital represents the "characteristics of social organization, networks, rules, and trust that facilitate coordination and cooperation for mutual benefit" (Krishna \& Shrader, 2000; Putnam, 1995). Social capital is multifaceted and has two main components: a structural component that reflects the nature and intensity of an individual's participation in community networks; and a cognitive component, which refers to the perceived quality of an individual's social relationships (Grootaert, Narayan, Nyhan Jones, \& Woolcock, 2004).

The association between social capital and PTSD, according to proposed theories, includes general mechanisms by which social capital may affect mental health and specific pathways through which social capital may inhibit the development of PTSD. The proposed protective 
effect of social capital on the development of several mental health disorders takes place at the individual and ecologic levels. At the individual level, social capital may provide individuals with resources, such as a sense of belonging, purpose, security, self-esteem and equity, to cope with adverse circumstances. These resources - which are beneficial psychological states - may result in greater motivation for self-care, lower exposure to stressors, improved coping mechanisms, and reduced perceived impact of stressful events. All of these in turn lead to diminished exposure to chronic psychological stress (De Silva, Huttly et al., 2007; Galea, Acierno et al., 2006; Kawachi \& Berkman, 2001; Wilkinson, 2002). At the ecological level, social capital may aid in the reduction of poverty, lessening poverty's impact and promoting community-level efficacy. These factors may potentially lead to increased adoption of healthy behaviors and control of risky behaviors in the community, as well as improved access to general-and mental health-related information and services (De Silva, Huttly et al., 2007; Ellaway, Macintyre, \& Kearns, 2001; Grootaert \& Van Bastelaer, 2001; Kawachi \& Berkman, 2001).

The specific psychological and biological mechanisms through which structural and cognitive social capital affects the development of PTSD remain unclear (Galea, Hadley, \& Rudenstein, 2006; Guay, Billette, \& Marchand, 2006). Social support, one of the components of structural social capital, has been proposed as an important variable that modulates the development and persistence of PTSD in an individual following a traumatic event (Brewin \& Holmes, 2003). Specifically, social support - which represents the nature and quantity of an individual's social interactions - affects the individual's cognitive processing of the traumatic event, as well as his/her emotional state and coping strategies. These mechanisms in turn explain the presence or absence of many PTSD symptoms, such as intrusive thoughts, avoidance of thinking about the event, social withdrawal and poor disclosure of the event to others (Ehlers \& Clark, 2000; Lepore, 2001; Williams \& Joseph, 1999). The relationship between social capital and PTSD in the aftermath of disasters is particularly relevant since the social fabric - which represents structural and cognitive social capital - is typically weakened in such contexts (Hobfoll et al., 2007; Hurtado, Kawachi, \& Sudarsky, 2011) and since disaster victims are more vulnerable to developing PTSD and/or other mental health problems (Kawachi \& Subramanian, 2006).

Studies in different settings have explored the relationship between social capital and PTSD in the short-term post-natural disaster context, with limited studies examining the persistence of PTSD beyond one year post-disaster. Some studies explored the association between social capital and PTSD in the year following the natural disaster (Ali et al., 2011; Armenian et al., 2000; Cairo et al., 2010; Feng et al., 2007; Kaniasty \& Norris, 2008; Wang et al., 2000; Wind, Fordham, \& Komproe, 2011; Wind \& Komproe, 2012; Xu \& Song, 2011). A few studies examined this same association at 2 and 2.5 years post-disaster (Ali, Farooq, Bhatti, \& Kuroiwa, 2011; Armenian et al., 2000; Cairo et al., 2010; Feng et al., 2007; Kaniasty \& Norris, 2008; Wang et al., 2000; Wind et al., 2011; Wind \& Komproe, 2012; Xu \& Song, 2011), with one of them doing so longitudinally, at 6, 12, 18 and 24 months after the event (Kaniasty \& Norris, 2008). In the context of disasters, social capital has been proposed as leading to enhanced community resilience, resources and capabilities to deal with the post-disaster scenario (Norris, Stevens, Pfefferbaum, Wyche, \& Pfefferbaum, 2008; Wilkinson, 2002). Further studies are critical to providing the evidence 
to inform interventions that can lessen the economic and health burden associated with PTSD in post-disaster settings in the short- and long-term.

Despite important variations in both PTSD and social capital between countries, few studies have evaluated the role of social capital on post-disaster PTSD in developing countries, particularly in Latin America or Peru. This is important because the nature, sources and levels of social capital vary between different cultural settings, and thus need to be explored independently in each context (De Silva, Harpham, Huttly, Bartolini, \& Penny, 2007; De Silva, Huttly et al., 2007; Szreter \& Woolcock, 2004). Culture determines how social capital is conceived and implemented (Taylor, 2007). Cross-cultural differences in social capital may be explained by the intrinsic characteristics of societies: individualism-collectivism, status identity, specific-holistic orientation, and tolerance for ambiguity (De Luque \& Sommer, 2000; Triandis, 1993). In addition, differences in the tendency of societies to trust and the cognitive processes used to generate trust may also underlie the cross-cultural differences in social capital (Doney, Cannon, \& Mullen, 1998; Fukuyama, 1995).

Individualism and collectivism relate to the primacy people in a society place on themselves over their aggregated social group (De Luque \& Sommer, 2000; Triandis, 1993) and both structures impact structural and cognitive social capital in different ways. Collectivist societies tend to give preference to the group over the individual, whereas the converse is true for individualist societies. Across contexts, industrialized, developed societies have become increasingly individualist, whereas less developed, traditional societies have remained collectivist (Hofstede, 1991). For example, Latin American countries are generally collectivist societies in which the family represents the basic social group (Gomez \& Sanchez, 2005). Collectivist societies tend to exhibit less trust in others, and particularly in strangers, than individualist societies (Yamagishi, Cook, \& Watabe, 1998). In individualist societies, people are more likely to associate voluntarily with and trust others (Allik \& Realo, 2004). Thus, collectivist societies are generally less open to establishing new relationships with "outsiders," in turn limiting the potential to develop structural social capital (Allik \& Realo, 2004). Instead, members of collectivist societies tend to seek out stable, predictable relationships with individuals that have proven to be trustworthy (Doney et al., 1998). Traditional collective societies also tend to view relationships in a more holistic way and form relationships that transcend many facets of life (professional, personal, etc.) (De Luque \& Sommer, 2000). In contrast, individualist societies tend to exhibit higher tolerance for ambiguity and establish relationships with "outsiders" that are usually focused on obtaining an outcome (Doney et al., 1998).

Cultural differences are also crucial for shaping the relationships that occur among members of a society, and determine how structural social capital is created in a society. Status identity relates to the definition of social status on the basis of culture-specific attributes (De Luque \& Sommer, 2000), which can impact structural social capital. High status identity societies tend to recognize individuals for their social status over their achievements, resulting in benefits for individuals with a high social status and restricting interaction between members with different statuses. In general, Latin American countries are high status identity societies (Gomez \& Sanchez, 2005), which may limit the potential for relationships between individuals from different statuses and hinder the potential for 
building structural social capital (De Luque \& Sommer, 2000; Taylor, 2007). With regard to cognitive social capital, individuals from collectivist societies tend to have higher levels of cognitive social value since they place more value on and more easily accept societal goals, norms and values (Taylor, 2007).

In Peru there are diverse opportunities to build structural and cognitive social capital, although engagement in these opportunities varies across communities and individuals. For example, for the community membership component of structural capital, there are national, regional and local union, community, women's, political, religious, credit and sports/social groups that individuals may join. For the individual support component, there are opportunities for support from families and friends as well as from international, national, regional and local governmental and nongovernmental organizations. National examples include the government-supported Community Kitchens (comedores populares), Glass of Milk (Vaso de Leche) and JUNTOS conditional cash transfer programs (Aramburú, Contraloría General de la República del Perú, \& Agencia de Cooperación Técnica Alemana, 2008). Finally, for the citizenship activities component, there are local organizations such as: residents' associations, in which elected community leaders and authorities organize work, distribute community resources and interact with external organizations; and self-defense committees (rondas campesinas), in which groups of men patrol the community to detect and punish animal thievery and solve local disputes. Opportunities to develop cognitive social capital also exist in Peru, through informal networks between community members, including friends, family and neighbors. Even though opportunities for building structural and even social capital are well-developed in Peru, how these opportunities play out varies within and across communities and individuals.

Several factors may result in an increased risk of chronic PTSD in Peru. First, the Peruvian population is repeatedly exposed to traumatic events. These events result from its geographic and climatic characteristics (i.e. its location in one of the most active seismic locations in the world and its vulnerability to the "El Niño" phenomenon) that cause periodic moderate to severe natural disasters (Young \& León, 2009); the war against terrorism in the past three decades (Pedersen, Tremblay, Errazuriz, \& Gamarra, 2008); and the high rates of crime and violence prevalent in the country (Heinemann \& Verner, 2006). Such cumulative exposure may enhance the country's vulnerability to developing PTSD after natural disasters (Breslau, Peterson, \& Schtulz, 2008; Brewin, Andrews, \& Valentine, 2000; Cohen, 2008; Neuner et al., 2004). Second, provision of and access to mental health services has been largely ignored in Peru (Fraser, 2007; Saraceno et al., 2007; Saxena, Thornicroft, Knapp, \& Whiteford, 2007), despite high prevalences of mental health disorders in the general population that remain undiagnosed and untreated (Instituto Nacional de Salud Mental, 2007). This is compounded by limited resources that prevent the provision of psychosocial supportive interventions and the reconstruction of the lives of people affected by natural disasters (Fraser, 2007). One large study in Peru explored the link between social capital and mental health. Specifically, the study analyzed the association between social capital and common mental disorders (depression and anxiety) among mothers of young children in different settings in Peru. Results showed that social capital 
has differential effects on depression and anxiety in this population (De Silva, Huttly et al., 2007).

In this context, we aimed to examine the association between cognitive and structural social capital and chronic PTSD among survivors of the 2007 Pisco Earthquake living in periurban and urban areas of province of Pisco, Peru, the province hardest hit by the earthquake in terms of deaths and destruction of buildings (Organización Panamericana de la Salud, 2010), four years post-disaster.

\section{Methods}

\section{Study design and setting}

We conducted a population-based cross-sectional survey in Pisco, Peru, in order to examine the association between social capital and PTSD 4 years after the 2007 Pisco earthquake.

Pisco is one of the five provinces of the department of Ica, Peru, $253 \mathrm{~km}$ to the southeast of Lima. The province of Pisco has 126,000 inhabitants who live in eight districts (INEI, 2008). Before the 2007 earthquake, Pisco was a poor province, whose main economic activities were agriculture, crafting and fishing. About 55\% of the houses were built with stones, mud, thatch, and other rudimentary materials. Access to basic services was limited: $36 \%$ of houses lacked public water supply, $34 \%$ lacked electricity, and $51 \%$ lacked access to the public waste drainage system (Municipalidad Provincial de Pisco \& Sistema Nacional de Defensa Civil, 2009, p. 80). In addition, 63\% of people living in urban and peri-urban Pisco had completed high school (INEI, 2008).

\section{The 2007 earthquake}

On August 15th 2007 (6:40 pm local time), a 7.9 magnitude earthquake with a duration of $210 \mathrm{~s}$ struck Pisco. Its epicenter was located $74 \mathrm{Km}$ west of the city of Pisco (one of the province's eight districts), at a depth of $39 \mathrm{~km}$ in the Pacific Ocean. The earthquake was cataloged as the worst Peruvian earthquake in the last 100 years and the longest in Peru's history.

The earthquake caused major damages, with great part of the impact concentrated in Pisco. Overall, 596 persons were killed, 1292 were injured, and 320,000-465,000 were affected. Despite the fact that the province of Pisco is home to only $18 \%$ of the population of the Department of Ica, $64 \%$ of earthquake-related deaths occurred in Pisco and $86 \%$ of its houses were affected, mainly due to their rudimentary construction. Of the two hospitals in Pisco, one sustained severe damages (losing 95\% of its hospitalization capacity) and the other was completely destroyed. Widespread blackouts, communication failure, water outages, sewage collapse, and severe damage to transport routes also occurred (Organización Panamericana de la Salud, 2010). Four years after the earthquake, little progress had been made in the restoration of Pisco and the lives of its residents (El Comercio, 2012; Long-Chavez, 2012). 


\section{Participants}

This study included adult survivors of the 2007 Pisco earthquake who resided in urban and peri-urban areas of 5 districts of the province of Pisco. Participants were randomly selected using a complex multi-stage sampling design. Inclusion criteria for the study included: age older than 21 years and residence in the current district during the 2007 Pisco earthquake. First, we selected five of the eight districts of Pisco based on the severity of the damages caused by the earthquake: two severely affected districts ( $\geq 45 \%$ of houses destroyed or severely damaged), one moderately affected district ( $₫ 45 \%$ of houses mildly damaged), and two mildly affected districts ( $\geq 40 \%$ of the houses mildly damaged or unaffected). The districts selected were: Pisco and San Clemente (severely affected); Independencia (moderately affected); and San Andres and Paracas (mildly affected). Then, we selected blocks and households from updated maps of the districts using systematic random sampling. Finally, in each selected house, we randomly selected one participant from all eligible household members. Interviewers visited the houses at different days and times of the morning, afternoon and evening to contact potential participants.

We anticipated that a sample size of 900 participants would result in $80 \%$ power to detect a prevalence ratio of PTSD of 1.88 (corresponding to an odds ratio of 2.00) in participants with low versus high social capital using a two-tailed exact test. This considers a prevalence of PTSD of $8 \%$ among participants with high social capital, a significance level of $5 \%$, and a design effect of 1.25 (to account for the complex survey design used). Since we anticipated a non-response proportion of $10 \%$ and a non-eligibility proportion of 5\%, we planned to screen approximately 1100 individuals to participate in the study.

Of the 1119 individuals screened to participate, $87(7.7 \%)$ did not fulfill the eligibility criteria [52 (4.6\%) had an age <21 years and $35(3.1 \%)$ were not in Pisco during the earthquake] and were not included in the study. In addition, $22(2.0 \%)$ individuals did not consent to participate and were also not included. Thus, 1012 (90.4\%) individuals were enrolled in the study [168 (16.6\%) from San Andrés, 180 (17.8\%) from Independencia, 225 (22.2\%) from Paracas, 222 (21.9\%) from Pisco, and 217 (21.5\%) from San Clemente].

\section{Data collection}

Data collection took place between July and September 2011. We used an interviewerapplied, paper-and-pencil survey comprised of 3 parts: i) a general socio-demographic questionnaire, ii) a validated Spanish translation of the PTSD Checklist - Civilian version (PCL-C), and iii) a validated Spanish translation of the Adapted Social Capital Assessment Tool (SASCAT). In applying the PCL-C to ascertain the presence of PTSD, we asked participants to respond specifically about symptoms related to the 2007 Pisco Earthquake. The survey team consisted of 4 interviewers, all of whom had a background in health (two nurses, a health center administrator, and a nurse assistant) and experience conducting health surveys. The team underwent 3 training sessions, directed by the lead author. In addition, we conducted a pilot study to test and adjust the instrument prior to initiating data collection. The pilot study was conducted with 20 adult volunteers from the district of Pisco from June 23-24, 2011. The volunteers were males and females of different ages. The pilot study was planned, implemented and evaluated by the lead author. The interviewer team recorded the 
times for the informed consent process and the completion of the questionnaires. Volunteers then participated in respondent debriefing during which the interviewers asked participants whether they understood the questions, if the interviewer instructions were clear, and if they had any suggestions for changes or improvements to the questions or response options (Hughes, 2004). The research team made minimal changes to the survey instruments following the pilot.

\section{Socio-demographic questionnaire}

This questionnaire contained 14 questions about socio-demographic characteristics (age, gender, marital status, religion, birthplace, education level and socio-economic status), personal and family history of mental illness, and variables related to the 2007 Pisco earthquake (severity of personal injuries, loss of family members, and severity of home damage). These questions were based on the Peruvian DHS (ENDES) survey and other surveys administered by the Peruvian National Institute of Statistics and Informatics (INEI), as well as instruments used in previous studies about earthquakes in Peru (Cairo et al., 2010).

\section{PTSD checklist - civilian version (PCL-C)}

We measured the presence of PTSD-related symptoms using a previously validated Spanish version of the PCL-C (Miles, Marshall, \& Schell, 2008; Vera-Villarroel, Zych, Celis-Atenas, Córdova-Rubio, \& Buela-Casal, 2011). The PCL-C has been widely used for population screening, as a feasible and accurate alternative to a full psychiatric clinical evaluation (Ruggiero, Del Ben, Scotti, \& Rabalais, 2003; Ruggiero, Rheingold, Resnick, Kilpatrick, \& Galea, 2006). The PCL-C assesses the presence of PTSD-related symptoms through 17 questions about the frequency with which the respondent has experienced a specific PTSDrelated symptom in the previous month. Answers are rated on a scale ranging from 1 (Never) to 5 (Always) and the total score is calculated as a simple sum of these ratings. A total score greater than 43 points was considered as indicative of the presence of PTSD (Blanchard, Jones-Alexander, Buckley, \& Forneris, 1996). The PCL-C had high internal consistency (Cronbach's alpha of 0.83 ) in this study.

\section{Adapted social capital assessment (SASCAT)}

The SASCAT is widely used to evaluate two dimensions of social capital: structural social capital and cognitive social capital. It was translated to Spanish and validated in Peru with 2771 caregivers from different regions of the country by De Silva et al. (2006). The structural component assesses group membership, support (emotional, economic and/or assistance) received from community groups and individuals, and involvement in citizenship activities in the previous year. The cognitive component evaluates the following: trust in the community, interpersonal relationships among community members, sense of belonging to the community, and perception that other community members may try to take advantage of oneself if they had the chance. The score on the structural component was categorized into quartiles and subsequently dichotomized into high (second, third, and fourth quartiles) and low (first quartile) structural social capital, as previously reported in a study on social capital and mental health in Peru (Loret de Mola et al., 2012). The score on the cognitive 
component was categorized into low (1-2 points) and high (3-4 points) cognitive social capital, as recommended by De Silva et al. (De Silva et al., 2006).

\section{Data analysis}

Statistical analysis was performed using STATA 11.0 for Windows (StataCorp LP, College Station, TX; USA). Bivariate analyses evaluating the association between PTSD and the socio-demographic, clinical and earthquake-related variables were conducted using the t-test and Mann-Whitney test for continuous variables and the chi-squared test for categorical variables, as appropriate. Multivariable analysis was conducted using prevalence ratio regression; specifically, we used Poisson regression with robust variance estimation to estimate the prevalence ratio (PR) of PTSD by levels of cognitive and structural social capital, after adjusting for relevant confounders (Barros \& Hirakata, 2003; Deddens \& Petersen, 2008). We chose to estimate the prevalence ratio, rather than the odds ratio, as a measure of association because the prevalence ratio is a more natural measure of association considering the chronic nature and high prevalence (>10\%) of the PTSD outcome. In this situation, an odds ratio poorly approximates the prevalence ratio, thus requiring direct estimation of this quantity (Barros \& Hirakata, 2003; Behrens, Taeger, Wellman, \& Keil, 2004; Thompson, Myers, \& Krisbel, 1998). Confounding variables were included in the multivariable analysis if they were significantly associated with both the outcome and the exposure in the bivariate analysis or on theoretical grounds, if the literature supported their role as confounders. All statistical analyses accounted for the multistage sampling used in the study.

\section{Ethical considerations}

This study received ethical approval from the Human Ethics Committee at Universidad Peruana Cayetano Heredia, in Lima, Peru, on November 2010 (reference \#57285). All study participants gave verbal informed consent prior to participating in the study.

\section{Results}

A total of 1012 individuals participated in the study (response rate $=90.4 \%$ ). The sociodemographic and earthquake-related characteristics of the study population are presented in Table 1. The study population was predominantly female, with a mean age of 43.1 (95\% CI: 38.7-47.4). Most participants were married or cohabitating (72.1\%), Catholic (79.7\%), with complete high school education (68.2\%), and low socio-economic status (73.5\%). Nearly two-thirds of the study population was at home during the earthquake and over one-third reported severe damages to their homes. Only $5 \%$ and $10 \%$ of the study population reported having personal or family history of mental illness, respectively. A small fraction of individuals received medical care for injuries suffered in the earthquake, and one-tenth lost a family member in the event. In terms of social capital, over half of the study population had high cognitive social capital and over two-thirds had high structural social capital. The prevalence of chronic PTSD in the study population was $15.9 \%$ (95\% CI: 12.3-19.8).

Table 2 shows the prevalence of PTSD by socio-demographic, clinical and earthquakerelated characteristics. The cognitive social capital score on the SASCAT was inversely 
associated with the PTSD score on the PCL-C $(p<0.01)$, while the structural social capital score was not associated with the PTSD score $(p=0.58)$. Specifically, those with high cognitive social capital had an almost two times lower prevalence of chronic PTSD than those with low cognitive social capital. Regarding the socio-demographic and earthquakerelated factors, PTSD was associated with a female gender, older age, separated/divorced marital status, lower education level, lower socioeconomic status, and higher severity of personal injuries.

Table 3 shows the crude and adjusted prevalence ratios (PR) of chronic PTSD by cognitive and structural social capital, as well as by socio-demographic, clinical and earthquakerelated characteristics. Cognitive social capital continued to be significantly associated with chronic PTSD $(p<0.01)$, but no association was observed between structural social capital and chronic PTSD $(p=0.23)$. After adjusting for all confounders, the prevalence of chronic PTSD among participants with low cognitive social capital was $83 \%$ higher than those with high cognitive social capital (PR $=1.83 ; 95 \%$ CI: 1.50, 2.22; $p<0.01)$. On the other hand, structural social capital was not independently associated with chronic PTSD (PR 1.44; 95\% CI: $0.70,2.97 ; p=0.23$ ).

\section{Discussion}

This study found that higher cognitive social capital is independently associated with lower prevalence of chronic PTSD among survivors of the 2007 Earthquake residing in Pisco, Peru, even 48 months after the disaster occurred. Participants with high cognitive social capital had a prevalence of chronic PTSD nearly twice as low as those with low cognitive social capital, even after adjusting for key confounders. No association was found between the structural dimension of social capital and chronic PTSD.

Social capital has been associated with several mental health outcomes (Almedom, 2005; De Silva, Huttly et al., 2007; Kawachi \& Berkman, 2001; Kripper \& Sapag, 2009; McKenzie et al., 2002; Whitley \& McKenzie, 2005), although evidence for specific psychiatric disorders including PTSD has been more limited. Furthermore, the few studies that have focused on the occurrence of PTSD were set in the immediate post-disaster setting, rather than the longterm persistence of PTSD (i.e. after 1-2 years) (Brewin et al., 2000; Cairo et al., 2010). Nevertheless, there are several similarities between our and earlier results. Previous studies have found a protective association between social capital (or some of its components) and the occurrence of PTSD (Ali et al., 2011; Wind et al., 2011; Wind \& Komproe, 2012), which parallels the association we found between cognitive social capital and chronic PTSD. In addition, and congruent with our results, previous studies evaluating cognitive and structural social capital have found differential associations between the cognitive and structural dimensions of social capital and PTSD (Wind et al., 2011; Wind \& Komproe, 2012). It has been postulated that the different associations between cognitive and structural social capital and PTSD arise from the mediating role of cognitive social capital in the relationship between structural social capital and PTSD (Wind \& Komproe, 2012). Because cognitive social capital is a more proximal determinant of PTSD, it tends to exhibit a more consistent, stronger association with the outcome-PTSD - than the more distal determinant of structural social capital. This follows the theoretical framework proposed by Putnam 
(2001) and Woolcock (2001), which argues that participation in social interactions and networks foster trust (Putnam, 2001; Woolcock, 2001). Although the reverse scenario is also plausible (that it is actually trust that favors more participation) (Brehm \& Rahn, 1997), there is some evidence that supports the proximal mediation of the effects of structural social capital by cognitive social capital (Veenstra, 2002). Nevertheless, the relationship between structural and cognitive social capital is complex, and longitudinal studies are needed to disentangle the direction of causality.

A related point of discussion is that it is possible to have high structural and low cognitive social capital within the same person. For example, it is possible for an individual to be involved in several community groups, receive support from multiple individuals and/or participate in citizenship activities (high structural social capital) yet not feel connected or trusting of his or her community (low cognitive social capital). In a multi-country study on maternal social capital and mental health, for example, about 2 in 3 mothers in Peru and Ethiopia reported receiving support from 1 to 2 or more individuals, that being one component of high structural social capital. However, high cognitive social capital was much lower in Peru (54.8\%) than in Ethiopia (88.9\%) (De Silva \& Harpham, 2007).

Interestingly, we found a high prevalence of PTSD (15.9\%; 95\% CI: 12.3, 19.8) despite the passing of several years since the disaster. Previous literature has demonstrated that as many as $30 \%$ of the cases of PTSD arising after exposure to a disaster will take a chronic course. Given that a study conducted in the city of Pisco eight months after the 2007 Earthquake (2008) found a prevalence of PTSD of 25\%, we anticipated a maximum prevalence of PTSD of $8 \%$. Nevertheless, we found a significantly higher prevalence of PTSD $(p<0.01)$. This may be attributed to local and cultural factors. Mental health has long been stigmatized in Peru and Latin America and, as mentioned above, mental health care and prevention programs have been and continue to be very limited and inefficient. The availability of mental health services during and after natural disasters and in the provinces of Peru is even more limited (Dirección General de Gestión del Desarrollo de Recursos Humanos, 2011; Fraser, 2007; Instituto Nacional de Salud Mental, 2007; Zevallos, Pastor, \& Moscoso, 2011). In addition, the resource limitations prevalent in Peru - as in most of Latin America complicate the adaptation and recovery of the population from the social, economic, health and psychological consequences of natural disasters. Moreover, the constraints and lethargy in the government's response to these catastrophes further complicate the reconstruction of the lives of the affected (El Comercio, 2012; Long-Chavez, 2012).

It is important to mention that much controversy exists in the research community about: the distinction between "normal" psychological distress related to life events and PTSD as a mental health pathology; and whether or not the prevalence of PTSD can be effectively measured in population-level studies. According to authors critical of the current Western psychiatric categorization of PTSD, diagnosis of this condition and development of related interventions should be re-evaluated using a more critical lens (Summerfield, 2001, 2004; Wakefield, 2007). Nevertheless, this interesting approach escapes the scope of our study. For our population-based study, we employed the PCL-C as a screening instrument since it has high internal consistency and validity (Vera-Villarroel et al., 2011) and since it was previously shown to be accurate for population-level estimates of PTSD (Ruggiero et al., 
2003, 2006). We believe that this instrument effectively allowed us to screen for probable Post Traumatic Stress Disorder among those living in Pisco post-disaster.

Our study has several limitations that should be taken into account when evaluating its findings. First, the cross-sectional design precludes establishment of a temporal or causal relationship between social capital and PTSD and limits the possibility of studying potential variations in the effect of social capital and other variables over time. Second, our study only surveyed urban and peri-urban residents. Thus our results may not be directly applicable to residents of rural settlements. Although it is expected that such individuals are at high-risk for mental health disorders and exhibit low levels of social capital, we were unable to include them in the study for logistic reasons. Study findings may be generalized to urban and peri-urban residents of low-resource communities in Peru and Latin America, but should not be uncritically extrapolated to other groups. Third, our study sample had significantly more females than males. We strove to include both groups by visiting households for interviews at different times of day (morning, afternoon, evening). However, given the long working hours and temporary travel for work among males in the communities, it was difficult to find males at home and include them. Fourth, although the prevalence of PTSD may have been underestimated due to social desirability bias (given the stigma associated with mental health disorders in Peru), this bias has been found to be more important in the acute trauma setting (Vazquez \& Perez-Sales, 2007). In this study, this bias was partially addressed by anonymity and population-friendly phrasing of questions. Fifth, study results may be subject to common method bias, as both PTSD and social capital were assessed by self-report, at only the individual level and at one point in time. Finally, recall bias may also have affected our results. However, the prominence of the 2007 earthquake in the respondents' lives and the use of significant events to help the participant answer the questionnaire accurately probably reduced the potential impact of such bias on our results.

Despite these limitations, this study is one of the first studies of chronic post-disaster PTSD conducted in Latin America, a setting where several factors result in high vulnerability to post-disaster PTSD and where the cultural and socioeconomic context may result in unique sources, types and levels of social capital. That the study is population-based with complex random sampling and high participant response rates further contributes to the generalizability of its results, at least in the urban setting. We believe that this study contributes to delineating the potentially protective role of cognitive social capital on the persistence of chronic PTSD in a resource-limited country in Latin America, and highlights the need for further research and the development of effective preventive strategies for this and other vulnerable populations. These findings underscore the importance of individuallevel cognitive social capital as a protective factor against the occurrence of PTSD in a postdisaster setting and contribute to understanding the nature of such relationships in a resource-limited population in Latin America. Further experimental evidence is needed to determine the potential causal effect of social capital. These results may have public health implications. For example, pre- and post-disaster community-based interventions that catalyze and foster dimensions of cognitive social capital may aid in ameliorating the effect of earthquakes and other natural disasters on populations with high vulnerability to such events and poor access to mental health and other support services. 


\section{Acknowledgments}

The authors would like to thank the faculty and students of the Masters in Epidemiological Research of Universidad Peruana Cayetano Heredia and the U.S. Naval Medical Research Unit 6 (NAMRU-6), NIH/FIC grant 2D43 TW007393 for their overall contributions, guidance and suggestions on study design, data analysis and manuscript preparation. This article was prepared as one of the products of the aforementioned program. Also, the authors would like to thank the interviewer team, the Peruvian American Medical Society (PAMS) mission of Pisco and the population of Pisco, who contributed so much to this study.

\section{References}

Ali M, Farooq N, Bhatti MA, Kuroiwa C. Assessment of prevalence and determinants of posttraumatic stress disorder in survivors of earthquake in Pakistan using Davidson Trauma Scale. Journal of Affective Disorders. 2011; 136:238-243. [PubMed: 22209270]

Almedom AM. Social capital and mental health: an interdisciplinary review of primary evidence. Social Science \& Medicine. 2005; 61:943-964. [PubMed: 15955397]

Allik J, Realo A. Individualism-collectivism and social capital. Journal of Cross-Cultural Psychology. 2004; 35:29-49.

Aramburú, CE.; Contraloría General de la República del Perú, \& Agencia de Cooperación Técnica Alemana (GTZ). Programas sociales en el Perú. Elementos para una propuesta desde el control gubernamental. Lima: Contraloría General de la República del Perú; 2008.

Armenian HK, Morikawa M, Melkonian AK, Hovanesian AP, Haroutunian N, Saigh PA. Loss as a determinant of PTSD in a cohort of adult survivors of the 1988 earthquake in Armenia: implications for policy. Acta Psychiatrica Scandinavica. 2000; 102:58-64. [PubMed: 10892611]

Barros AJ, Hirakata VN. Alternatives for logistic regression in cross-sectional studies: an empirical comparison of models that directly estimate the prevalence ratio. BMC Medical Research Methodology. 2003; 3:21. [PubMed: 14567763]

Behrens T, Taeger D, Wellmann J, Keil U. Different methods to calculate effect estimates in crosssectional studies. A comparison between prevalence odds ratio and prevalence ratio. Methods of Information in Medicine. 2004; 43:505-509. [PubMed: 15702210]

Blanchard EB, Jones-Alexander J, Buckley TC, Forneris CA. Psychometric properties of the PTSD Checklist (PCL). Behaviour Research and Therapy. 1996; 34:669-673. [PubMed: 8870294]

Brehm J, Rahn W. Individual level evidence for the causes and consequences of social capital. American Journal of Political Science. 1997; 41:999-1023.

Breslau N, Peterson EL, Schultz LR. A second look at prior trauma and the posttraumatic stress disorder effects of subsequent trauma: a prospective epidemiological study. Archives of General Psychiatry. 2008; 65:431-437. [PubMed: 18391131]

Brewin CR, Andrews B, Valentine JD. Meta-analysis of risk factors for posttraumatic stress disorder in trauma-exposed adults. Journal of Consulting and Clinical Psychology. 2000; 68:748-766. [PubMed: 11068961]

Brewin CR, Holmes EA. Psychological theories of posttraumatic stress disorder. Clinical Psychology Review. 2003; 23:339-376. [PubMed: 12729677]

Cairo JB, Dutta S, Haq N, Hashmi S, Kasl S, Bellido E. The prevalence of posttraumatic stress disorder among adult earthquake survivors in Peru. Disaster Medicine and Public Health Preparedness. 2010; 4:39-46. [PubMed: 20389194]

Cohen RE. Lecciones aprendidas durante desastres naturales: 1970-2007. Revista Peruana de Medicina Experimental y Salud Pública. 2008; 25:109-117.

Davidson JR, McFarlane AC. The extent and impact of mental health problems after disaster. Journal of Clinical Psychiatry. 2006; 67(Suppl. 2):9-14. [PubMed: 16602810]

De Luque MFS, Sommer SM. The impact of culture on feedback-seeking behavior: an integrated model and propositions. The Academy of Management Review. 2000; 25:829-849.

De Silva MJ, Harpham T. Maternal social capital and child nutritional status in four developing countries. Health and Place. 2007; 13:341-355. [PubMed: 16621665] 
De Silva MJ, Harpham T, Huttly SR, Bartolini R, Penny ME. Understanding sources and types of social capital in Peru. Community Development Journal. 2007; 42:19-33.

De Silva MJ, Harpham T, Tuan T, Bartolini R, Penny ME, Huttly SR. Psychometric and cognitive validation of a social capital measurement tool in Peru and Vietnam. Social Science \& Medicine. 2006; 62:941-953. [PubMed: 16095787]

De Silva MJ, Huttly SR, Harpham T, Kenward MG. Social capital and mental health: a comparative analysis of four low income countries. Social Science \& Medicine. 2007; 64:5-20. [PubMed: 17045716]

Deddens JA, Petersen MR. Approaches for estimating prevalence ratios. Occupational and Environmental Medicine. 2008; 65(481):486-501.

Dirección General de Gestión del Desarrollo de Recursos Humanos. Recursos humanos en salud al 2011: Evidencias para la toma de decisiones. Lima: Ministerio de Salud del Perú; 2011.

Doney PM, Cannon JP, Mullen MR. Understanding the influence of national culture on the development of trust. Academy of Management Review. 1998; 23:601-620.

Ehlers A, Clark DM. A cognitive model of posttraumatic stress disorder. Behaviour Research and Therapy. 2000; 38:319-345. [PubMed: 10761279]

El Comercio. A 5 años del terremoto en Ica: desidia, precariedad y corrupción. El Comercio. 2012 Aug 12. Retrieved from http://elcomercio.pe/actualidad/1454827/noticia-anos-terremoto-ica-desidiaprecariedad-corrupcion

Ellaway A, Macintyre S, Kearns A. Perceptions of place and health in socially contrasting neighbourhoods. Urban Studies. 2001; 38:2299-2316.

Feng S, Tan H, Benjamin A, Wen S, Liu A, Zhou J. Social support and posttraumatic stress disorder among flood victims in Hunan, China. Annals of Epidemiology. 2007; 17:827-833. [PubMed: 17606382]

Foa EB, Stein DJ, McFarlane AC. Symptomatology and psychopathology of mental health problems after disaster. Journal of Clinical Psychiatry. 2006; 67(Suppl. 2):15-25. [PubMed: 16602811]

Fraser B. Earthquake highlights mental-health issues in Peru. Lancet. 2007; 370:815-816. [PubMed: 17847162]

Fukuyama, F. Trust: The social virtues and creation of prosperity. New York: The Free Press; 1995.

Galea S, Acierno R, Ruggiero K, Resnick H, Tracy M, Kilpatrick D. Social context and the psychobiology of posttraumatic stress. Annals of the New York Academy of Sciences. 2006; 1071:231-241. [PubMed: 16891574]

Galea S, Hadley C, Rudenstein S. Social context and the health consequences of disasters. American Journal of Disaster Medicine. 2006; 1:37-47. [PubMed: 18274042]

Galea S, Nandi A, Vlahov D. The epidemiology of post-traumatic stress disorder after disasters. Epidemiologic Reviews. 2005; 27:78-91. [PubMed: 15958429]

Gomez C, Sanchez JI. HR's strategic role within MNCs: helping build social capital in Latin America. International Journal of Human Resource Management. 2005; 16:2189-2200.

Grootaert, C.; Narayan, D.; Nyhan Jones, V.; Woolcock, M. Measuring social capital An integrated questionnaire. Washington DC: The World Bank; 2004.

Grootaert, C.; Van Bastelaer, T. Understanding and measuring social capital: A synthesis of findings and recommendations from the social capital initiative. Washington DC: The World Bank; 2001

Guay S, Billette V, Marchand A. Exploring the links between post-traumatic stress disorder and social support: processes and potential research avenues. Journal of Traumatic Stress. 2006; 19:327-338. [PubMed: 16788995]

Heinemann, A.; Verner, D. Crime and violence in development: A literature review of Latin America and the Caribbean. Washington DC: World Bank; 2006.

Hobfoll SE, Watson P, Bell CC, Bryant RA, Brymer MJ, Friedman MJ. Five essential elements of immediate and mid-term mass trauma intervention: empirical evidence. Psychiatry. 2007; 70:283315. [PubMed: 18181708]

Hofstede, G. Cultures and organizations: Software of the mind. New York: MGraw-Hill; 1991.

Hughes, KA. Comparing pretesting methods: Cognitive interviews, respondent debriefing, and behavior coding. Washington DC: U.S. Bureau of the Census; 2004. 
Hurtado D, Kawachi I, Sudarsky J. Social capital and self-rated health in Colombia: the good, the bad and the ugly. Social Science \& Medicine. 2011; 72:584-590. [PubMed: 21185633]

INEI. Censos Nacionales 2007: XI de Población y VI de Vivienda. Perfil socio-demográfico del Peru. Lima: Instituto Nacional de Estadística e Informática; 2008.

Instituto Nacional de Salud Mental. Estudio epidemiológico de salud mental en la costa peruana 2006. Informe general. Anales de Salud Mental, XXIII. 2007:1-226.

International Federation of Red Cross and Red Crescent Societies. World disaster report 2012. Focus on forced migration and displacement. Geneva: International Federation of Red Cross and Red Crescent Societies; 2012.

Kaniasty K, Norris FH. Longitudinal linkages between perceived social support and posttraumatic stress symptoms: sequential roles of social causation and social selection. Journal of Traumatic Stress. 2008; 21:274-281. [PubMed: 18553415]

Kawachi I, Berkman LF. Social ties and mental health. Journal of Urban Health. 2001; 78:458-467. [PubMed: 11564849]

Kawachi I, Kennedy BP, Lochner K, Prothrow-Stith D. Social capital, income inequality, and mortality. American Journal of Public Health. 1997; 87:1491-1498. [PubMed: 9314802]

Kawachi I, Subramanian SV. Measuring and modeling the social and geographic context of trauma: a multilevel modeling approach. Journal of Traumatic Stress. 2006; 19:195-203. [PubMed: 16612828]

Kessler RC, Sonnega A, Bromet E, Hughes M, Nelson CB. Post-traumatic stress disorder in the National Comorbidity Survey. Archives of General Psychiatry. 1995; 52:1048-1060. [PubMed: 7492257]

Kripper CE, Sapag JE. Social capital and health in Latin America and the Caribbean: a systematic review. Revista Panamericana de Salud Publica. 2009; 25:162-170. [PubMed: 19531312]

Krishna, A.; Shrader, E. Cross-cultural measures of social capital: A tool and results from India and Panama. The World Bank Social Development Family Environmentally and Socially Sustainable Development Network; 2000.

Lepore, SJ. A social-cognitive processing model of emotional adjustment to cancer. In: Baum, A.; Andersen, BL., editors. Psychological interventions for cancer. Washington DC: American Psychological Association; 2001. p. 99-116.

Long-Chavez, A. Pisco earthquake: Four years later, Peruvian refugees receive water and power. Huffington Post; 2012.

Loret de Mola C, Stanojevic S, Ruiz P, Gilman RH, Smeeth L, Miranda JJ. The effect of rural-to-urban migration on social capital and common mental disorders: PERU MIGRANT study. Social Psychiatry and Psychiatric Epidemiology. 2012; 47:967-973. [PubMed: 21667301]

McFarlane A. The long-term costs of traumatic stress: intertwined physical and psychological consequences. World Psychiatry. 2010; 9:3-10. [PubMed: 20148146]

McKenzie K, Whitley R, Weich S. Social capital and mental health. British Journal of Psychiatry. 2002; 181:280-283. [PubMed: 12356653]

Miles JNV, Marshall GN, Schell TL. Spanish and English versions of the PTSD checklist - civilian version (PCL-C): testing for differential item functioning. Journal of Trauma and Stress. 2008; 21:369-376.

Municipalidad Provincial de Pisco \& Sistema Nacional de Defensa Civil. Plan provincial de prevención y atención de desastres de la provincia de Pisco, región Ica 2009-2019. Lima, Peru: Comité Provincial de Defensa Civil e Pisco; 2009.

Murayama H, Fujiwara Y, Kawachi I. Social capital and health: a review of prospective multilevel studies. Journal of Epidemiology. 2012; 22:179-181. [PubMed: 22447212]

Neria Y, Nandi A, Galea S. Post-traumatic stress disorder following disasters: a systematic review. Psychological Medicine. 2008; 38:467-480. [PubMed: 17803838]

Neuner F, Schauer M, Karunakara U, Klaschik C, Robert C, Elbert T. Psychological trauma and evidence for enhanced vulnerability for post-traumatic stress disorder through previous trauma among West Nile refugees. BMC Psychiatry. 2004; 4:34. [PubMed: 15504233] 
Norris FH, Friedman MJ, Watson PJ, Byrne CM, Diaz E, Kaniasty K. 60,000 disaster victims speak: part I. An empirical review of the empirical literature, 1981-2001. Psychiatry. 2002; 54:207-239. [PubMed: 12405079]

Norris FH, Stevens SP, Pfefferbaum B, Wyche KF, Pfefferbaum RL. Community resilience as a metaphor, theory, set of capacities, and strategy for disaster readiness. American Journal of Community Psychology. 2008; 41:127-150. [PubMed: 18157631]

Organización Panamericana de la Salud. Terremoto de Pisco, Perú - A dos años del sismo, crónica y lecciones aprendidas en el sector salud. Washington DC, USA: Organización Panamericana de la Salud; 2010.

Pedersen D, Tremblay J, Errazuriz C, Gamarra J. The sequelae of political violence: assessing trauma, suffering and dislocation in the Peruvian highlands. Social Science \& Medicine. 2008; 67:205217. [PubMed: 18423959]

Putnam R. Bowling alone: America's declining social capital. Journal of Democracy. 1995; 6:64-78.

Putnam R. Social capital: measurement and consequences. Isuma: Canadian Journal of Policy Research. 2001; 2:41-51.

Ruggiero KJ, Del Ben K, Scotti JR, Rabalais AE. Psychometric properties of the PTSD checklistcivilian version. Journal of Traumatic Stress. 2003; 16:495-502. [PubMed: 14584634]

Ruggiero KJ, Rheingold AA, Resnick HS, Kilpatrick DG, Galea S. Comparison of two widely used PTSD-screening instruments: implications for public mental health planning. Journal of Traumatic Stress. 2006; 19:699-707. [PubMed: 17075907]

Saraceno B, Van Ommeren M, Batniji R, Cohen A, Gureje O, Mahoney J. Barriers to improvement of mental health services in low-income and middle-income countries. Lancet. 2007; 370:1164-1174. [PubMed: 17804061]

Sareen J, Cox BJ, Stein MB, Afifi TO, Fleet C, Asmunsson GJG. Physical and mental comorbidity, disability, and suicidal behavior associated with posttraumatic stress disorder in a large community sample. Psychosomatic Medicine. 2007; 69:242-248. [PubMed: 17401056]

Saxena S, Thornicroft G, Knapp M, Whiteford H. Resources for mental health: scarcity, inequity, and inefficiency. Lancet. 2007; 370:878-889. [PubMed: 17804062]

Spitzer C, Barnow S, Völzke H, John U, Freybrger H, Grabe HJ. Trauma, posttraumatic stress disorder, and physical illness: findings from the general population. Psychosomatic Medicine. 2009; 71:1012-1017. [PubMed: 19834051]

Summerfield D. The invention of post-traumatic stress disorder and the social usefulness of a psychiatric category. BMJ (Clinical Research Ed.). 2001; 322:95-98.

Summerfield, D. Cross-cultural perspectives on the medicalisation of human suffering. In: Rosen, G., editor. Posttraumatic stress disorder Issues and controversies. Chichester: John Wiley; 2004. p. 233-245.

Szreter S, Woolcock M. Health by association? Social capital, social theory, and the political economy of public health. International Journal of Epidemiology. 2004; 33:650-667. [PubMed: 15282219]

Taylor S. Creating social capital in MNCs: the international human resource management challenge. Human Resource Management Journal. 2007; 17:336-354.

Thompson ML, Myers JE, Krisbel D. Prevalence odds ratio or prevalence ratio in the analysis of cross sectional data: what is to be done? Occupational and Environmental Medicine. 1998; 55:271-277.

Triandis HC. Collectivism and individualism as cultural syndromes. Cross-cultural Research. 1993; 27:155-180.

Vazquez C, Perez-Sales P. Planning needs and services after collective trauma: should we look for the symptoms of PTSD? Intervention. 2007; 5:27-40.

Veenstra G. Explicating social capital: trust and participation in the civil space. Canadian Journal of Sociology. 2002; 27:547-572.

Vera-Villarroel P, Zych I, Celis-Atenas K, Córdova-Rubio N, Buela-Casal G. Chilean validation of the posttraumatic stress disorder checklist e civilian version (PCL-C) after the earthquake on February 27, 2010. Psychological Reports. 2011; 109:47-58. [PubMed: 22049647]

Wakefield JC. The concept of mental disorder: diagnostic implications of the harmful dysfunction analysis. World Psychiatry. 2007; 6:149-156. [PubMed: 18188432] 
Wang X, Gao L, Shinfuku N, Zhang H, Zhao C, Shen Y. Longitudinal study of earthquake-related PTSD in a randomly selected community sample in North China. American Journal of Psychiatry. 2000; 157:1260-1266. [PubMed: 10910788]

Whitley R, McKenzie K. Social capital and psychiatry: review of the literature. Harvard Review of Psychiatry. 2005; 13:71-84. [PubMed: 16020022]

Wilkinson, RG. Unhealthy societies: The afflictions of inequality. London: Routledge; 2002.

Williams, R.; Joseph, S. An integrative psychosocial model of PTSD. In: Yule, W., editor. Posttraumatic stress disorder: Concepts and therapy. Chichester: Wiley; 1999. p. 297-314.

Wind TR, Fordham M, Komproe IH. Social capital and post-disaster mental health. Global Health Action. 2011; 4:6351.

Wind TR, Komproe IH. The mechanisms that associate community social capital with post-disaster mental health: a multilevel model. Social Science \& Medicine. 2012; 75:1715-1720. [PubMed: 22883254]

Woolcock M. The place of social capital in understanding social and economic outcomes. Isuma: Canadian Journal of Policy Research. 2001; 2:11-17.

Xu J, Song X. Posttraumatic stress disorder among survivors of the Wenchuan earthquake 1 year after: prevalence and risk factors. Comprehensive Psychiatry. 2011; 52:431-437. [PubMed: 21683180]

Yamagishi T, Cook KS, Watabe M. Uncertainty, trust and commitment formation in the United Stated and Japan. American Journal of Sociology. 1998; 104:165-194.

Yehuda R. Post-traumatic stress disorder. New England Journal of Medicine. 2002; 346:108-114. [PubMed: 11784878]

Young KR, León B. Natural hazards in Peru: causation and vulnerability. Developments in Earth Surface Processes. 2009; 13:165-180.

Zevallos L, Pastor R, Moscoso B. Oferta y demanda de medicos especialistas en los establecimientos de salud del Ministerio de Salud: brechas a nivel nacional, por regiones y tipo de especialidad. Revista Peruana de Medicina Experimental y Salud Pública. 2011; 28:177-185. [PubMed: 21845296] 
Table 1

Characteristics of the study population.

\begin{tabular}{|c|c|c|}
\hline \multirow[t]{2}{*}{ Characteristics } & \multirow{2}{*}{$\frac{\text { Un-weighted }}{N(\%)}$} & \multirow{2}{*}{$\frac{\text { Weighted }}{\%(95 \% \mathrm{CI})}$} \\
\hline & & \\
\hline \multicolumn{3}{|l|}{ Gender } \\
\hline Female & $677(66.9)$ & $67.8(65.7,69.9)$ \\
\hline Male & $335(33.1)$ & $32.2(30.1,34.3)$ \\
\hline Age (years) ${ }^{a}$ & 40.1 & $43.1(38.7,47.4)$ \\
\hline 20-29 years & $314(31.0)$ & $24.5(13.9,35.1)$ \\
\hline 30-39 years & $273(27.0)$ & $24.7(22.6,26.7)$ \\
\hline $40-49$ years & $151(14.9)$ & $15.3(13.3,17.4)$ \\
\hline $50-59$ years & $129(12.8)$ & $16.2(12.6,19.9)$ \\
\hline $60-69$ years & $87(8.6)$ & $11.6(7.3,15.9)$ \\
\hline$\geq 70$ years & $58(5.7)$ & $7.6(4.7,10.5)$ \\
\hline \multicolumn{3}{|l|}{ Marital status } \\
\hline Single & $224(22.2)$ & $20.4(15.7,26.0)$ \\
\hline Married/cohabitating & $721(71.3)$ & $72.1(68.5,75.5)$ \\
\hline Divorced/separated & $33(3.3)$ & $3.3(2.7,4.0)$ \\
\hline Widowed & $33(3.3)$ & $4.3(3.0,6.1)$ \\
\hline \multicolumn{3}{|l|}{ Religion } \\
\hline None & $70(6.9)$ & $4.7(2.3,9.3)$ \\
\hline Catholic & $773(76.4)$ & $79.7(74.0,84.4)$ \\
\hline Non-Catholic & $169(16.7)$ & $15.6(13.6,17.9)$ \\
\hline \multicolumn{3}{|l|}{ Education } \\
\hline None & $25(2.5)$ & $1.9(0.8,4.3)$ \\
\hline Primary school ( $1-6$ years) & $221(21.9)$ & $25.4(20.3,31.3)$ \\
\hline High school/university (>7 years) & $765(75.7)$ & $72.7(67.8,77.2)$ \\
\hline \multicolumn{3}{|l|}{ Socio-economic status $b$} \\
\hline Low & $779(77.0)$ & $73.5(67.4,78.9)$ \\
\hline Middle & $199(19.7)$ & $22.6(18.5,27.2)$ \\
\hline High & $34(3.4)$ & $3.9(2.6,5.8)$ \\
\hline \multicolumn{3}{|l|}{ Location during the earthquake } \\
\hline Own house & $590(58.6)$ & $63.2(56.3,69.5)$ \\
\hline Neighbor's/friend's house & $117(11.6)$ & $10.6(10.0,11.3)$ \\
\hline Public place & $300(29.8)$ & $26.2(20.4,33.0)$ \\
\hline \multicolumn{3}{|l|}{ Personal injuries } \\
\hline Hospitalized/ambulatory care & $40(4.0)$ & $6.4(3.6,10.9)$ \\
\hline Unaffected & $970(96.0)$ & $93.7(89.1,96.4)$ \\
\hline \multicolumn{3}{|l|}{ Housing damages } \\
\hline Destroyed/uninhabitable & $290(28.8)$ & $36.9(25.9,49.6)$ \\
\hline Moderately/severely damaged & $282(28.0)$ & $31.6(27.5,36.0)$ \\
\hline Unaffected/mildly damaged & $434(43.1)$ & $31.5(18.5,48.2)$ \\
\hline
\end{tabular}




\begin{tabular}{|c|c|c|}
\hline \multirow[t]{2}{*}{ Characteristics } & \multirow{2}{*}{$\frac{\text { Un-weighted }}{N(\%)}$} & \multirow{2}{*}{$\frac{\text { Weighted }}{\%(95 \% \mathrm{CI})}$} \\
\hline & & \\
\hline \multicolumn{3}{|c|}{ Loss of family members } \\
\hline Yes & $96(9.5)$ & $15.9(7.7,29.9)$ \\
\hline No & $910(90.5)$ & $84.1(70.1,92.3)$ \\
\hline \multicolumn{3}{|c|}{ History of mental illness } \\
\hline Present & $74(7.3)$ & $4.9(1.6,14.1)$ \\
\hline Absent & $936(92.7)$ & $95.1(85.9,98.4)$ \\
\hline \multicolumn{3}{|c|}{ Family history of mental illness } \\
\hline Yes & $112(11.1)$ & $10.1(7.5,13.4)$ \\
\hline No & $898(88.9)$ & $89.9(86.6,92.5)$ \\
\hline $95 \%$ CI: $95 \%$ Con & & \\
\hline
\end{tabular}




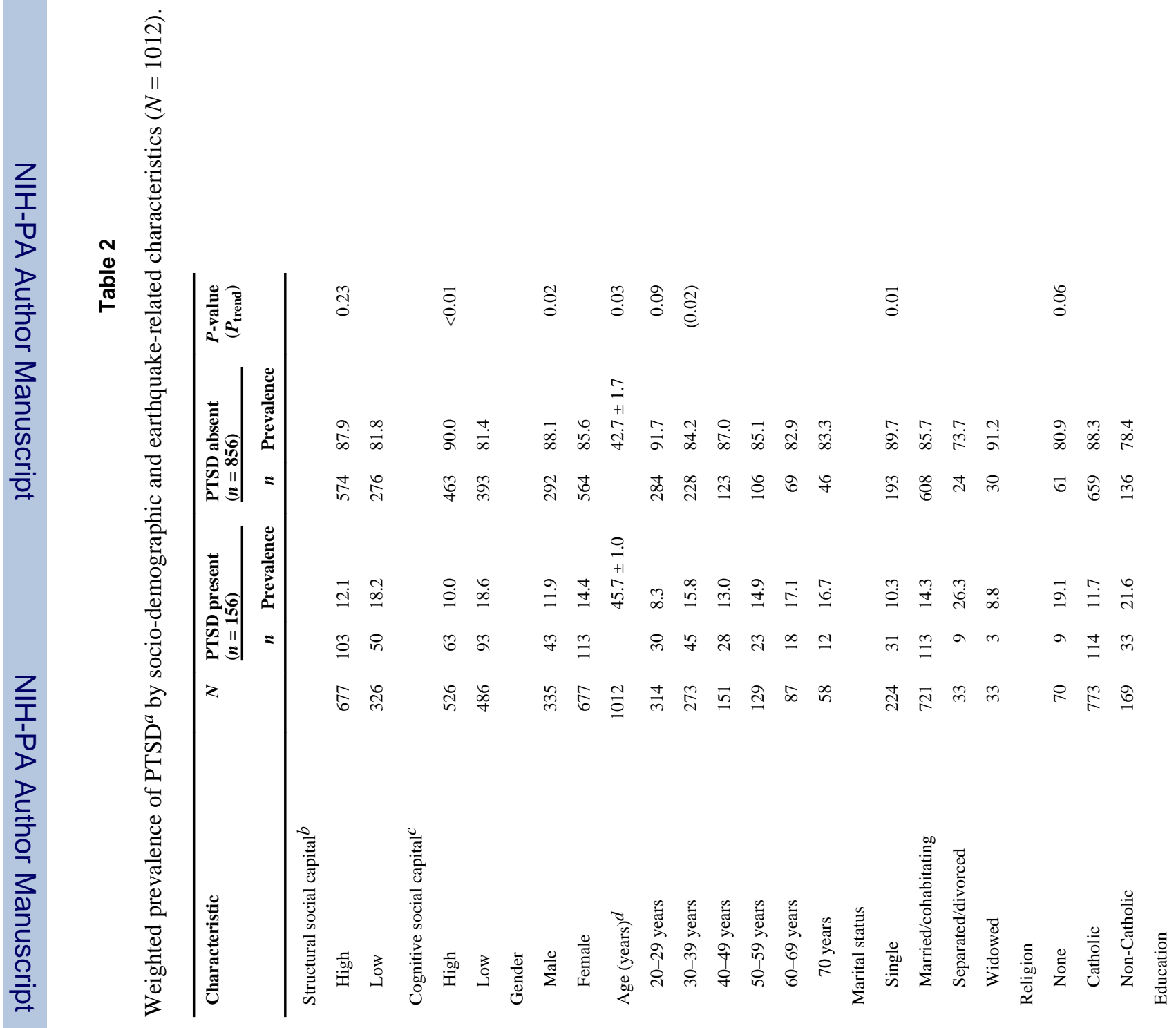




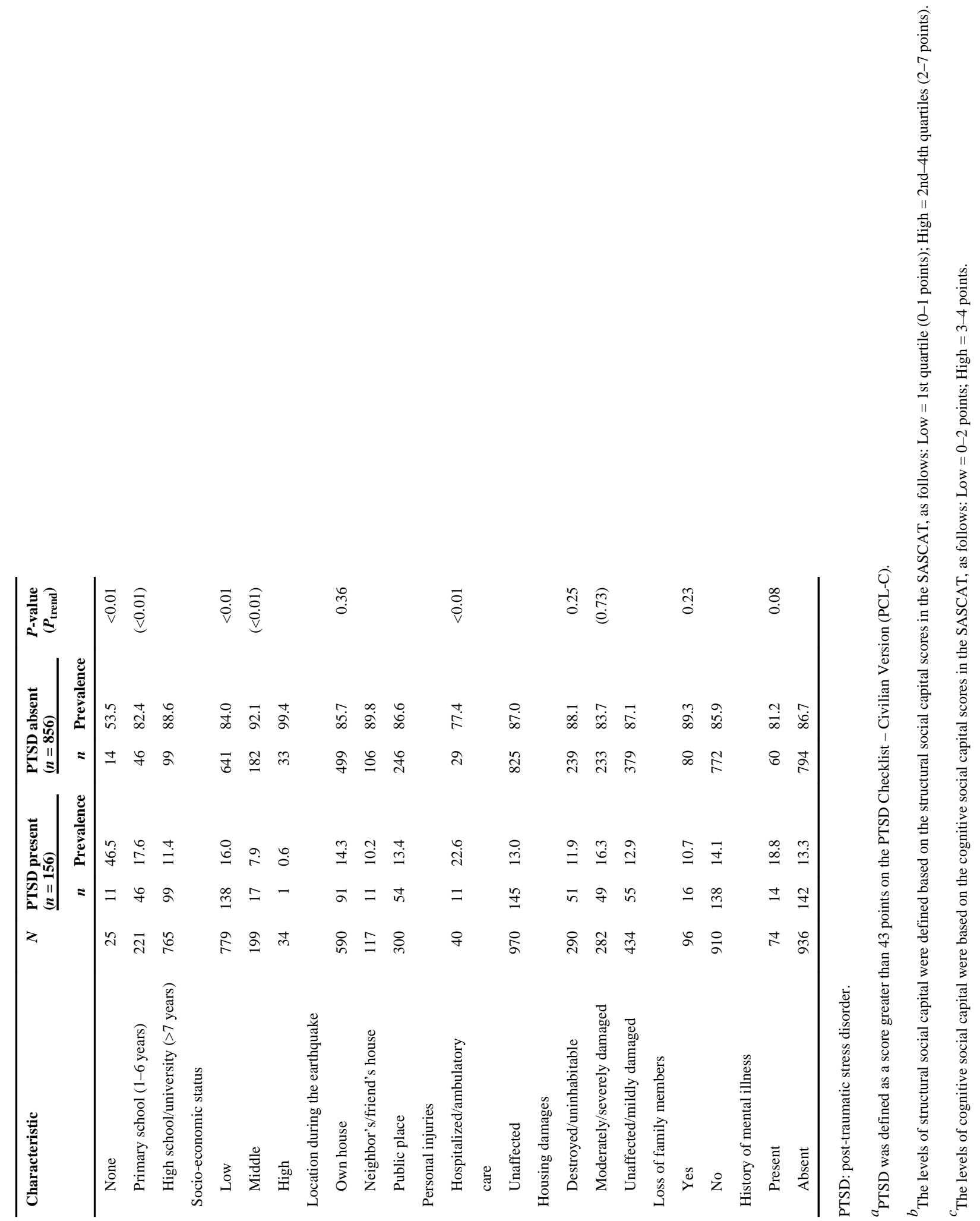


Table 3

Crude and adjusted prevalence ratios (PR) and 95\% confidence intervals (95\% CI) of post-traumatic stress disorder (PTSD) ${ }^{a}$ by social capital and socio-demographic, clinical and earthquake-related characteristics.

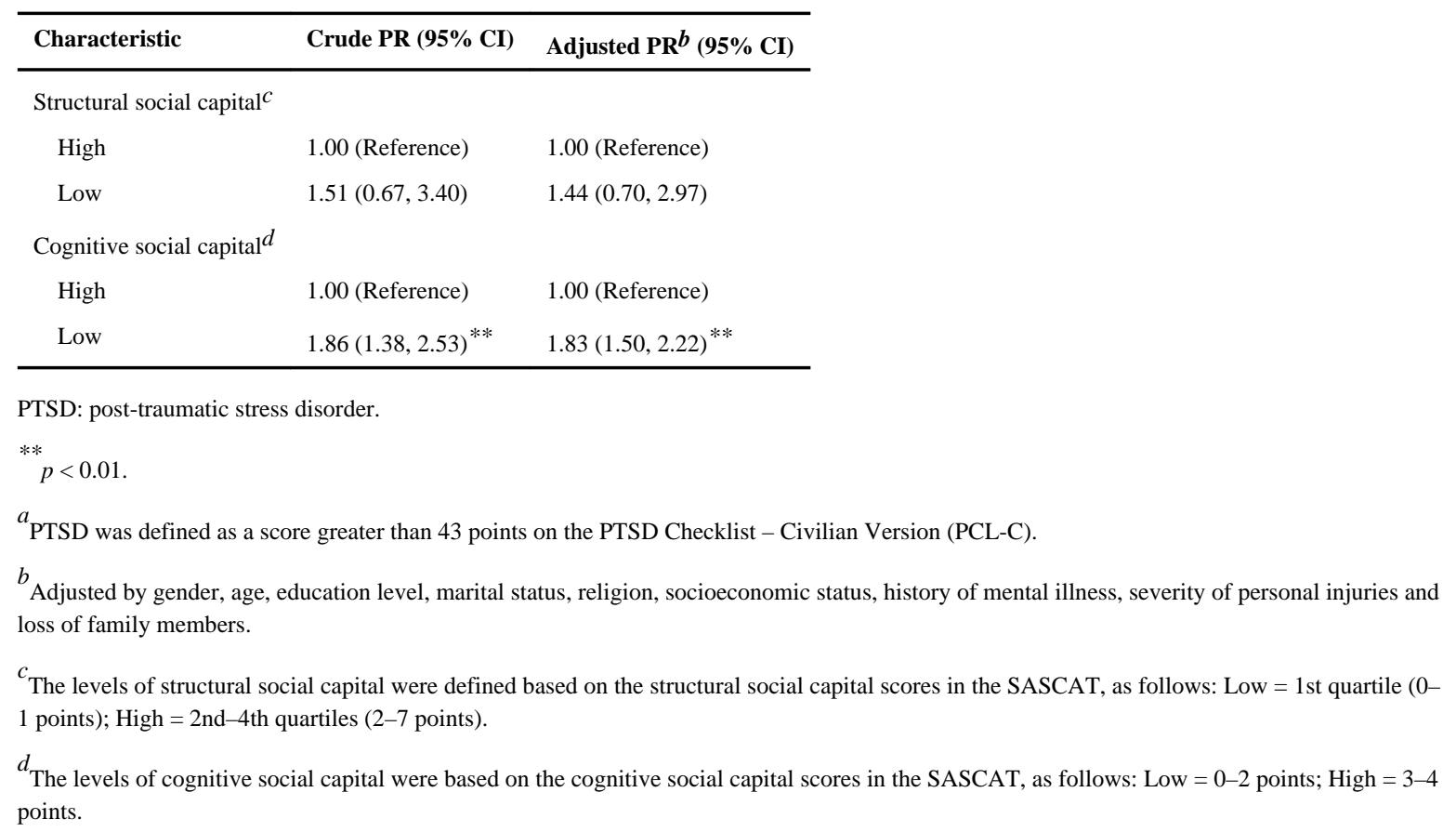

